\title{
Characterization of individual fly ash particles in surface snow at Urumqi Glacier No. 1, Eastern Tianshan
}

\author{
ZHANG XueLei $^{1 *}$, WU GuangJian ${ }^{1 *}$, YAO TanDong ${ }^{1,2}$, ZHANG ChengLong $^{1}$ \& YUE YaHui ${ }^{3}$ \\ ${ }^{1}$ Key Laboratory of Tibetan Environment Changes and Land Surface Processes, Institute of Tibetan Plateau Research, Chinese Academy of \\ Sciences, Beijing 100085, China; \\ ${ }^{2}$ State Key Laboratory of Cryospheric Science, Chinese Academy of Sciences, Lanzhou 730000, China; \\ ${ }^{3}$ Key Laboratory of Continental Collision and Plateau Uplift, Institute of Tibetan Plateau Research, Chinese Academy of Sciences, Beijing \\ 100085, China
}

Received March 3, 2011; accepted July 1, 2011; published online August 30, 2011

This research aimed to identify and characterize individual spherical fly ash particles extracted from surface snow at Urumqi Glacier No.1 (UG1), Eastern Tien Shan, central Asia. Characterization of the spherical particles (i.e. morphology, chemical composition and genesis) was obtained by scanning electron microscopy coupled with energy dispersive X-ray spectrometer (SEM-EDX). This method enabled the characterization of submicroscopic spherical particles, which were present in very small quantities. Spherical particles and agglomerates were identified according to their morphology in five snow samples. Prevalent particle types in all samples were granular spherical particles, hollow spherical particles, irregularly shaped carbonaceous particles and agglomerates. The vast majority of spherical particles in our samples had mostly smooth and glossy surfaces, although these particles varied in diameter and elemental composition. The diameter of fly ash particles ranged from 0.76 to $16.7 \mu \mathrm{m}$, with an average of $3.79 \mu \mathrm{m}$ (median: $3.21 \mu \mathrm{m}$ ). Individual particle analyses of elemental composition showed that particles formed in combustion were mainly composed of carbon, silicon, aluminum and trace elements (e.g. $\mathrm{Na}, \mathrm{K}, \mathrm{Ca}, \mathrm{Fe}$ ). Some spherical fly ash particles contained toxic heavy metals (e.g. $\mathrm{Pb}, \mathrm{Cr}, \mathrm{As}, \mathrm{Zn}$ ), and indicated that fly ash particles acted as the main possible carriers of toxic heavy metals deposited in snow and ice of glaciers in high altitudes of central Asia. On the basis of chemical information obtained from EDX, the fly ash particles deposited in the snow could be classified into four types. Namely, Si-dominant particles, with average diameters of $3.24 \mu \mathrm{m}$ were formed by industrial coal combustion via high temperature processes in typical coal-fired heating stations and thermal power plants. Moreover, Fe-dominant particles, with average diameters of $3.82 \mu \mathrm{m}$, and Ti-dominant spherical particles formed by lower temperature processes in foundry and iron or steel plants. In addition, C-dominant particles, with average diameters of $8.43 \mu \mathrm{m}$, formed from unburned coal. Fe-dominant particles had larger average diameters than Sidominant particles, indicating that the former were easier to form and developed earlier in the furnace because of their differential melting points of compositional oxide. Backward air mass trajectory analysis suggests that the developed urban regions of central Asia contributed the primary fly ash particles from industrial combustion to the study site through the high-level westerlies jet steam.

fly-ash particles, individual particle characterization, SEM-EDX, chemical classification, Urumqi Glacier No.1

Citation: Zhang X L, Wu G J, Yao T D, et al. Characterization of individual fly ash particles in surface snow at Urumqi Glacier No. 1, Eastern Tianshan. Chinese Sci Bull, 2011, 56: 3464-3473, doi: 10.1007/s11434-011-4684-8

Fly-ash particles can be used as indicators of atmospheric deposition of pollutants from fossil-fuel combustion. Thus, analysis of fly-ash particles in insoluble particles has become increasingly important in studies of environmental pollution

*Corresponding authors (email: Wugj@itpcas.ac.cn; leixuezhang@itpcas.ac.cn) and atmospheric history. Most fly-ash studies have focused on black spheroidal carbonaceous particles (SCP) and inorganic ash spheres (IAS) $(>5 \mu \mathrm{m})$ produced from oil and coal combustion [1]. Several analyses of lake and ice cores have been used to record the content of fly ash to study the effect of post-industrial effects on the environment [2-4]. Air- 
borne particles of fly ash can also act as transporters of particle-associated contaminants, such as heavy metals, sulfur and organic components [5]. Thus, assuming that a suite of airborne particles within the same size range is transported by the same air masses, fly ash particle information may be used for tracing the origin and dispersal of contaminants.

The process for the removal of aerosol particles depends mainly on wet deposition [6], which represents $70 \%-85 \%$ of the tropospheric sink for carbonaceous aerosol particles [7]. Moreover, fly ash particles can be transported over long distances, and may reach remote regions, such as the Arctic and the Tibetan Plateau [8,9]. Snow is a natural collector and preservation agent, and an ideal medium for recording atmospheric constituents through wet and dry deposition [10]. Particles deposited on the surface of snow and glaciers may absorb high solar radiation and reduce the albedo intensity and accelerate the melting of snow and ice [11].

Although researchers have looked at pollen content in ice cores and surface snow [12-14], other similar-sized airborne particles, in particular SCP and IAS, have not received the same attention despite there being extensive sediment studies on them. Several investigations [15-18] have addressed the effects of aerosol particles on glaciers in the Tibetan Plateau and even the Arctic region, but little is known about fly ash particles in surface snow over central Asian alpine glaciers, especially with regard to their individual characterizations.

To improve our understanding of the physical and chemical properties of individual fly ash particles from surface snow, snow samples were collected from Urumqi Glacier No. 1 (UG1), eastern Tien Shan (Tianshan), from 2006 to 2007. The main purpose of this work is to determine the morphology, size distribution and chemical composition of individual fly ash particles using scanning electron microscopy coupled with energy dispersive X-ray spectrometer (SEM-EDX). Thus, the micro-properties of single particles can be used to trace possible contaminant sources of fly ash particles from UG1.

\section{Sampling and methods}

\subsection{Sample collection}

This project forms part of the Program for Glacier Processes Investigation, launched in 2002 by the Tianshan Glaciological Station. Snow samples were collected weekly or biweekly at the field observation site $\left(43^{\circ} 06^{\prime} \mathrm{N}, 86^{\circ} 49^{\prime} \mathrm{E}, 4130\right.$ $\mathrm{m}$ a.s.1.) in a percolation zone of the east branch of UG1. The mean annual air temperature and precipitation at the site were about $-9.1^{\circ} \mathrm{C}$ and $700 \mathrm{~mm}$ water equivalence, respectively. The high-level westerlies jet steam prevailed across the high mountains throughout the year.

Great effort was made to collect fresh, well-preserved surface snow. In this study, acid-cleaned wide-mouth Nalgene LDPE bottles were used both as sample scoops and containers. These bottles were kept frozen during transport to the laboratory before filtration. A total of 68 samples were collected during the sampling period between March 2006 and January 2008 [19]. Five of the snow samples (S6-25, S6-29, S6-33, S6-36 and S7-15) were melted at room temperature just before filtration, and they were filtered on polycarbonate filters (Millipore Corporation) with a diameter of $47 \mathrm{~mm}$ and a pore size of $0.8 \mu \mathrm{m}$. Thus, only particles with diameters larger than $0.8 \mu \mathrm{m}(800 \mathrm{~nm})$ were collected and analyzed. Specific information on the five snow samples is shown in Table 1. The filtrations were completed in a class 1000 clean room at the State Key Laboratory of Cryospheric Sciences, Lanzhou Cold and Arid Regions Environment and Engineering Research Institute, Chinese Academy of Sciences.

\subsection{Sample analyses}

Polycarbonate filters were best suited for SEM observation due to the smooth surface texture, which makes individual particles much easier to discern than other types [20]. First, approximately one tenth of the polycarbonate filter was cut and then glued to a standard $12.5 \mathrm{~mm}$ aluminum SEM stub using double-faced adhesive carbon tape (Figure 1). Then, the specimen was coated with a thin carbon film by the electric arc high vacuum method. A Zeiss EVO MAR 10 SEM equipped with EDX was used for manual analyses. Operating conditions were $20 \mathrm{kV}$ accelerating voltage and $480 \mathrm{pA}$ beam current with spectral acquisition times of $60 \mathrm{~s}$. SEM images were acquired at magnifications of 500, 1000, $2000,3000,5000$, and $10000 \times$. In the observational area, we searched for the regular spherical particles at magnifications lower than $2000 \times$ (about $60 \mu \mathrm{m}$ ) with a length of $12.5 \mathrm{~mm}$. Once the particles were found, we recorded their morphologies within other differential magnifications (Figure 1). The X-ray analysis system was equipped with an energy-dispersive $\mathrm{Si}(\mathrm{Li})$ detector, and super ultrathin window, allowing chemical elemental analysis $\left(\mathrm{Be}^{4}\right.$ to $\left.\mathrm{U}^{92}\right)$. Oxford INCA Energy software was used for quantitative analysis of individual particles. The weight percent of elements was calculated using standardless ZAF corrections [21]. The abundance of each oxide in the particles was determined with the standardized oxide method of EDX, which assumes that each element exists as oxide and sums

Table 1 Information on collected samples for SEM observations

\begin{tabular}{ccccc}
\hline Sample & $\begin{array}{c}\text { Collected } \\
\text { date }\end{array}$ & $\begin{array}{c}\text { Snow volume } \\
(\mathrm{mL})\end{array}$ & $\begin{array}{c}\text { Precipitation } \\
(\mathrm{mm})\end{array}$ & $\begin{array}{c}\text { Temperature } \\
\left({ }^{\circ} \mathrm{C}\right)\end{array}$ \\
\hline S6-25 & $2006-08-10$ & 139 & 0.1 & 7.1 \\
S6-29 & $2006-09-14$ & 97 & 0 & 4.9 \\
S6-33 & $2006-10-12$ & 97 & 1.2 & -0.2 \\
S6-36 & $2006-11-02$ & 91 & 0 & -3.4 \\
S7-15 & $2007-07-11$ & 171 & 7.6 & 5.8 \\
\hline
\end{tabular}




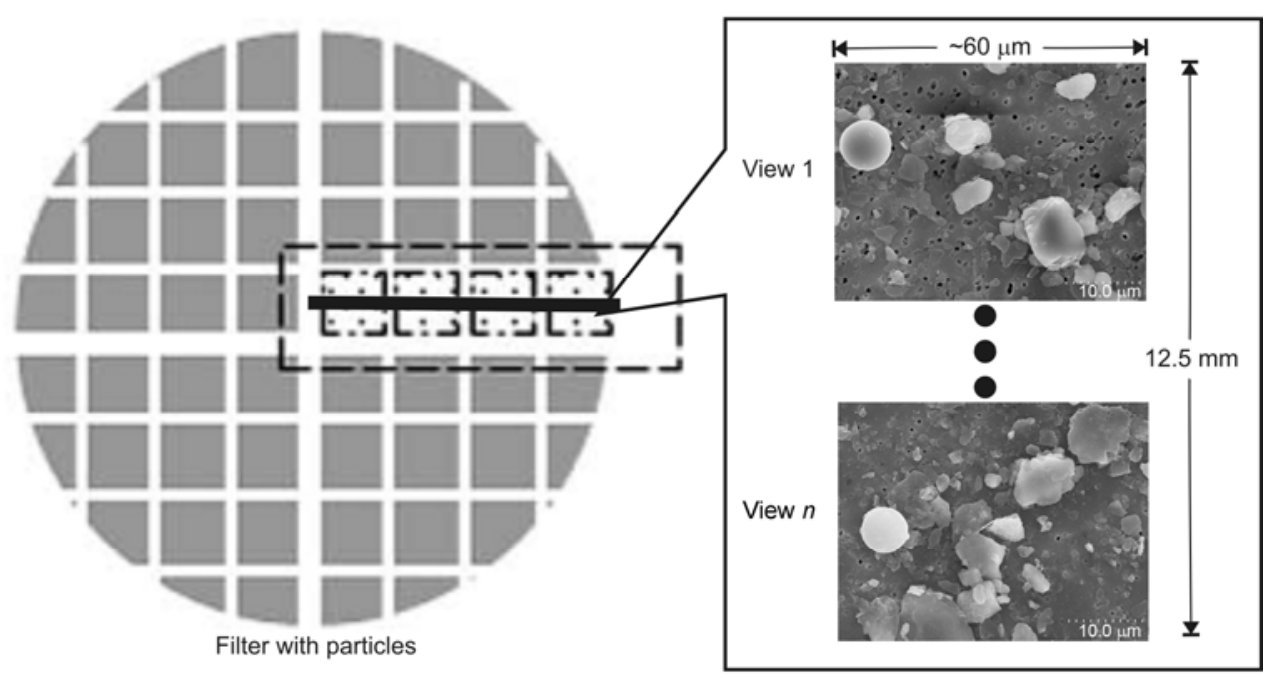

Figure 1 Diagram of observational method for particles with regular morphology.

the abundances of all detected elements to $100 \%$. About 500000 particles were observed at $2000 \times$ magnification within the magnified area $(\sim 60 \mu \mathrm{m} \times 12.5 \mathrm{~mm})$, but a total of 195 particles with regular shapes (including spherical carbon particles and biological particles) were analyzed by EDX to study their elemental composition and possible mineralogy.

The SEM images were further analyzed with the image processing and analysis software Image-Pro ${ }^{\circledR}$ Plus version 6.0 (Media Cybernetics, Inc. USA). We chose the manual measurement option to target each particle on the image, and the morphological parameters were automatically measured by the software [22]. Data were saved to Microsoft Excel for further processing. Finally, a total of 145 spherical fly ash particles were manually measured to study the size distribution and morphology of insoluble particles in snowfall.

\section{Results and discussion}

\subsection{Morphological analysis}

The size, shape and texture of particles are differentiating parameters under the microscope. In most cases, the factors that characterize particles are not their elementary forms, but the organization of their structures. To obtain the optimal perspective, different magnification levels are used for insoluble particles with different purpose. In this study, the lowest magnification $(500 \times)$ could discriminate on the order of tens of microns and the highest magnification $(10000 \times)$ can discriminate on the order of tens of nanometers. Comprehensive compositional and structural information can be obtained through this method.

The first level of identification is to distinguish between natural particles and anthropogenic spherical particles.
Morphological characteristics can be used to discriminate between these types, which are shown in Figure 2.

Natural particles are mainly composed of mineral particles that originated from land surface materials. Often, mineral particles have sharp edges, which break along a cleavage or fractures upon particle formation (Figure 2). If the mineral particles have been transported over great-distances, the morphologies of particles may show a certain degree of rounding.

Conversely, a number of regular morphologies are found among the insoluble particles from the surface snow of UG1. These spherical particles are never bigger than $20 \mu \mathrm{m}$ in diameter, and have a geometrical shape which excludes any possible explanation based on a crystalline genesis process (Figure 2). Most of the particles possess a seemingly smooth texture on their surfaces. Important compositional similarities are found on these particles. Heavy elements (e.g. Pb,

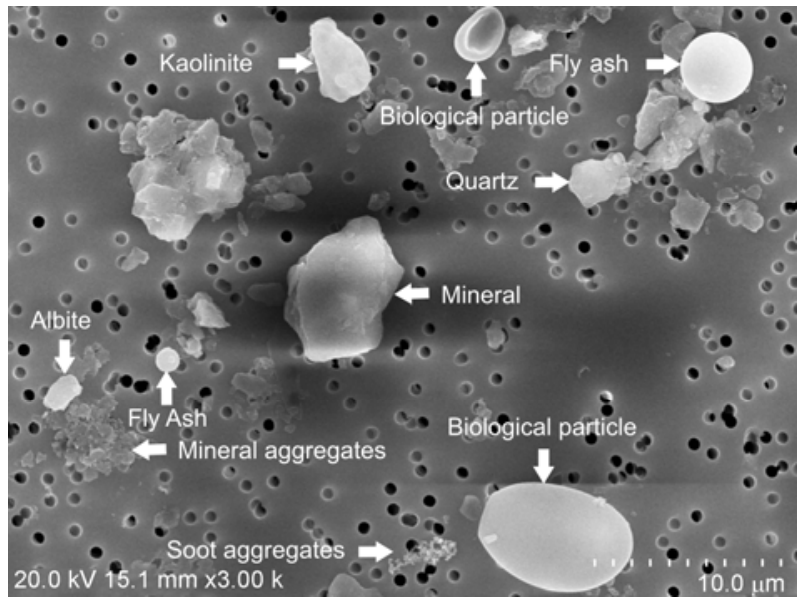

Figure 2 Typical morphology of different particles observed by SEM imaging. 
$\mathrm{Zn}$ and As) present in some of these spherical particles may be found in such high quantities that it is impossible to prove a natural origin for these particles.

Less abundant, but nonetheless important, biological particles with similar morphologies to spherical fly ash particles must be discriminated. Biological particles usually are symmetrical and tissue-like. Pollen is the most significant example of this type of particle, due to its abundance in nature. This characterization peculiarity allows us to distinguish biological particles from fly ash particles effectively (Figure 2). In the group of biological particles, we also found different types, although these particles represented a very small proportion of insoluble particle in the deposited snow. The spherical particles originating from combustion were characterized, in most cases, by a spherical shape caused by the melting process that occurs during their formation. This is a basic principle, and it establishes a structural distinction between soot particles, often originated from strongly energetic processes with chain shapes.

The vast majority of spherical particles in our samples usually had a smooth and glossy surface (Figure 2), although these particles varied in diameter and elemental composition. In this paper, the diameter of spherical particles ranged from 0.76 to $16.7 \mu \mathrm{m}$, with an average of $3.79 \mu \mathrm{m}$ (median:

\section{$3.21 \mu \mathrm{m})$}

As anticipated, the dominant particle types in all samples were granular spherical particles, hollow spherical particles, irregularly shaped carbonaceous particles and agglomerate particles. A primary classification of the most spherical fly ash particles deposited in the snow based on the morphology of fly ash particles, is illustrated in Table 2.

Smooth spherical particles, emanating from high temperature industrial combustion, are mostly characterized by a spherical shape, which results from melting processes that occur during their formation [23,24]. The cooling of small portions of melted material will be produced step-by-step. The melted material may suffer an ultimate reduction when it is finally released into the atmosphere from the furnace. In this manner, the existence of these spherical particles with different diameters may be justified. These particles are composed of basically silicon and aluminum mineral phases of technogenic origin, formed during high temperature industrial coal combustion $\left(1400-1500^{\circ} \mathrm{C}\right)$. Their composition may be used as an index of minerals or indicators for industrial high temperature processes [25]. These particles are typical of coal-fired heating stations and thermal power plants emissions $[25,26]$.

Hollow particles are formed during the combustion of

Table 2 Primary classification of the most spherical fly ash particles based on morphology

\begin{tabular}{llll}
\hline & Classification & Characteristics \\
\hline 1) Smooth spherical &
\end{tabular}

1) Smooth spherical

Spherical particles whose maximum diameter/mean diameter relationship is near to 1 , with smooth surface

2) Rough spherical

Spherical particles whose maximum diameter/mean diameter relationship is near to 1 , with rough surface

3) Irregular

Clearly defined particles, similar to glass fragments, with peaks or edges

4) Amorphous

Particles with an ill-defined appearance
Particle arising from combustion of mineral coal. Usually with a silicon or aluminum-silicon matrix

Particles arising from metal foundry ovens. Composed mainly of a wide variety of metallic elements in the form of oxides

A result of expulsion of gaseous materials from the particle interior, due to an increase in internal pressure or decrease in external pressure
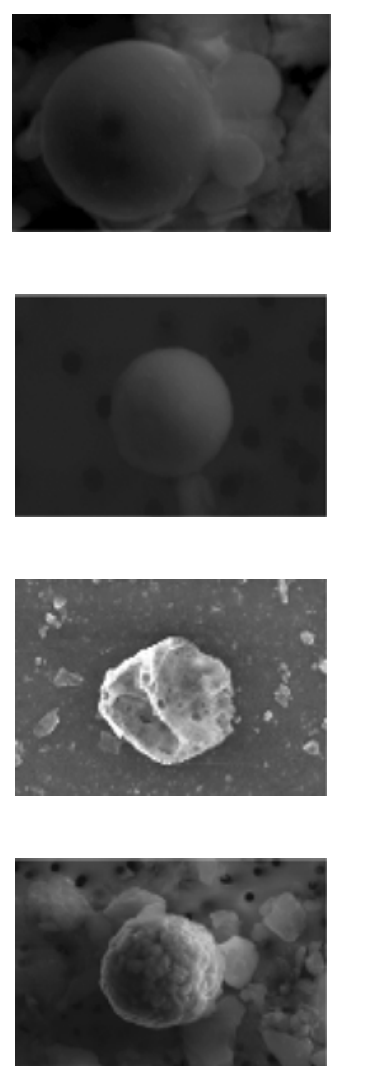

Particles that are formed by aggregations of other smaller units. Variable composition depending on their origin 
coal or fuel oil $[23,27]$. Both in fusion and cooking kilns, the average temperature of the gaseous emission are around $700-800^{\circ} \mathrm{C}$ and $250-300^{\circ} \mathrm{C}$, respectively [28]. During low temperature $\left(700-750^{\circ} \mathrm{C}\right)$ incomplete combustion, less porous hollow spherical particles were formed. The hollow spherical shape was a result of expulsion of gaseous materials from the particle interior, due to an increase in internal pressure or decrease in external pressure [23]. The presence of these particles was a consequence of abrupt changes in temperature during combustion processes. Only two or three hollow spherical particles were found in our sample, indicating that the fly ash particles mainly originated from combustion processes with constant temperatures.

Other types of particles also were found with morphologies showing an anthropogenic origin. These results were corroborated by the small size of the particles $(<1 \mu \mathrm{m})$. For example, grumose masses made up of very small particles immersed in a "spongy" mass were sampled (Figure 1 soot aggregates).

\subsection{Chemical analysis}

Spherical fly ash particles from different origins may possess morphologic and chemical differences. Integrated characterization of particles should encompass these two complementary aspects. Analysis of the elementary composition by EDX contributed additional information for classification and identification of possible origins of the captured spherical particles in our samples.

Fly ash particles showed different elemental levels and compositions depending on the process of combustion. Fly ash particles preserved in five snow samples mainly were composed of carbon, silicon, aluminum and trace elements (e.g. Na, K, Ca, Fe and Ti). These were different from the particles formed by combustion of liquid fuels from petroleum, for which carbon is usually the major element and are accompanied with trace elements (e.g. P, S, Cl) [29]. The EDX spectra of spherical fly ash particles with different morphologies are shown in Figure 3.

More unusual and unexpected in our sample were spherical particles comprising iron and other heavy metals, such as titanium, nickel and copper in variable ratios. We classified these particles as foundry spherical particles, which originated from steelwork factories. The EDX spectra of spherical particles, consisting of iron matrixes, with sulfur, silicon, nickel and low carbon contents, are shown in Figure $3(\mathrm{~g})$, (h), (i) and (j). Iron oxides of spherical particles sometimes occurred in the form of hematite $\left(\mathrm{Fe}_{2} \mathrm{O}_{3}\right)$, magnetite $\left(\mathrm{Fe}_{3} \mathrm{O}_{4}\right)$ and goethite $(\mathrm{FeO}(\mathrm{OH}))$. Morphologies of particle (g) and (h) (spherical shape and skeletal crystals in a glassy matrix) suggest that these particles were formed during the melting process of steel at very high temperatures, followed by rapid cooling [30]. These particles contained a great variety of trace metals, with iron frequently being the most abundant and characteristic element. Based on these char- acteristics, we speculated that these particles were most likely formed in high-temperature steel production processes or re-melting and refining processes of scrap steel, containing the aforementioned heavy metals as alloy components [31-33].

Another important issue in our study was the nature of the carrier of heavy metals to snow and glaciers. In general, less volatile elements, such as cadmium, cobalt, copper, chromium, iron, manganese, nickel, lead and zinc and mercury, were likely to be emitted to the atmosphere associated with fine particulate matter, as well as fly ash [34]. Meji [35] stated that gaseous arsenic, $\mathrm{As}_{2} \mathrm{O}_{3}$, is only present in flue gases if the concentration of calcium is less than $0.1 \%$. The elemental weight percent of calcium associated with spherical fly ash in the present study was $0.34 \%$ (Figure 4), which indicates that there may have been some chemical reaction between $\mathrm{As}$ and $\mathrm{Ca}$, perhaps as $\mathrm{Ca}_{3}\left(\mathrm{AsO}_{4}\right)_{2}$ [36,37]. Several studies have found that the intricate contamination of differential heavy metals in snow and ice cores come from the Himalayas and central Asia, but no one has illustrated possible contaminant approaches [38-40]. Furthermore, McConnell [41] also found that toxic heavy metals emitted by coal burning in the mid-latitudes were transported through the atmosphere and deposited in the Arctic regions. Consequently, we considered fly ash particles as one main mechanism for heavy metal deposition on snow and ice of glaciers in the high altitudes of central Asia.

\subsection{Chemical classification of the studied particles}

Using the chemical information derived from EDX, a general classification of the dominant fly ash particles deposited on the snow was produced. Such a classification is preliminary, and establishes an approach for the evaluation of anthropogenic pollution in terms of fly ash contents. The proposed classification is shown in Table 3.

Spherical particles with high content $(>90 \%)$ of carbon were classified as C-dominant particles, which were formed by unburned coal. Carbon is the dominant element in other spherical particles, but chemical classification is based on other main elements, such as $\mathrm{Si}, \mathrm{Fe}$ and $\mathrm{Ti}$.

The melting points of different oxides are enumerated in Table 4. As the melting points of $\mathrm{SiO}_{2}, \mathrm{Al}_{2} \mathrm{O}_{3}, \mathrm{MgO}$ and $\mathrm{CaO}$ are much higher than $\mathrm{Fe}_{2} \mathrm{O}_{3}$ and $\mathrm{TiO}_{2}$, Si-dominant spherical particles from coal combustion can be used as indicators for industrial high temperature processes [25], such as typical coal-fired heating stations and thermal power plants emissions [26]. Fe-dominant and Ti-dominant spherical particles from coal combustion can be used as indicators for lower temperature processes, such as foundry and iron and steel plants $[31,33]$. Four chemical species in each snow sample are illustrated in Figure 5.

According to our method of chemical classification, the particle number of Si-dominant particles was the most abundant in all five snow samples, and thus fly ash pollution from 

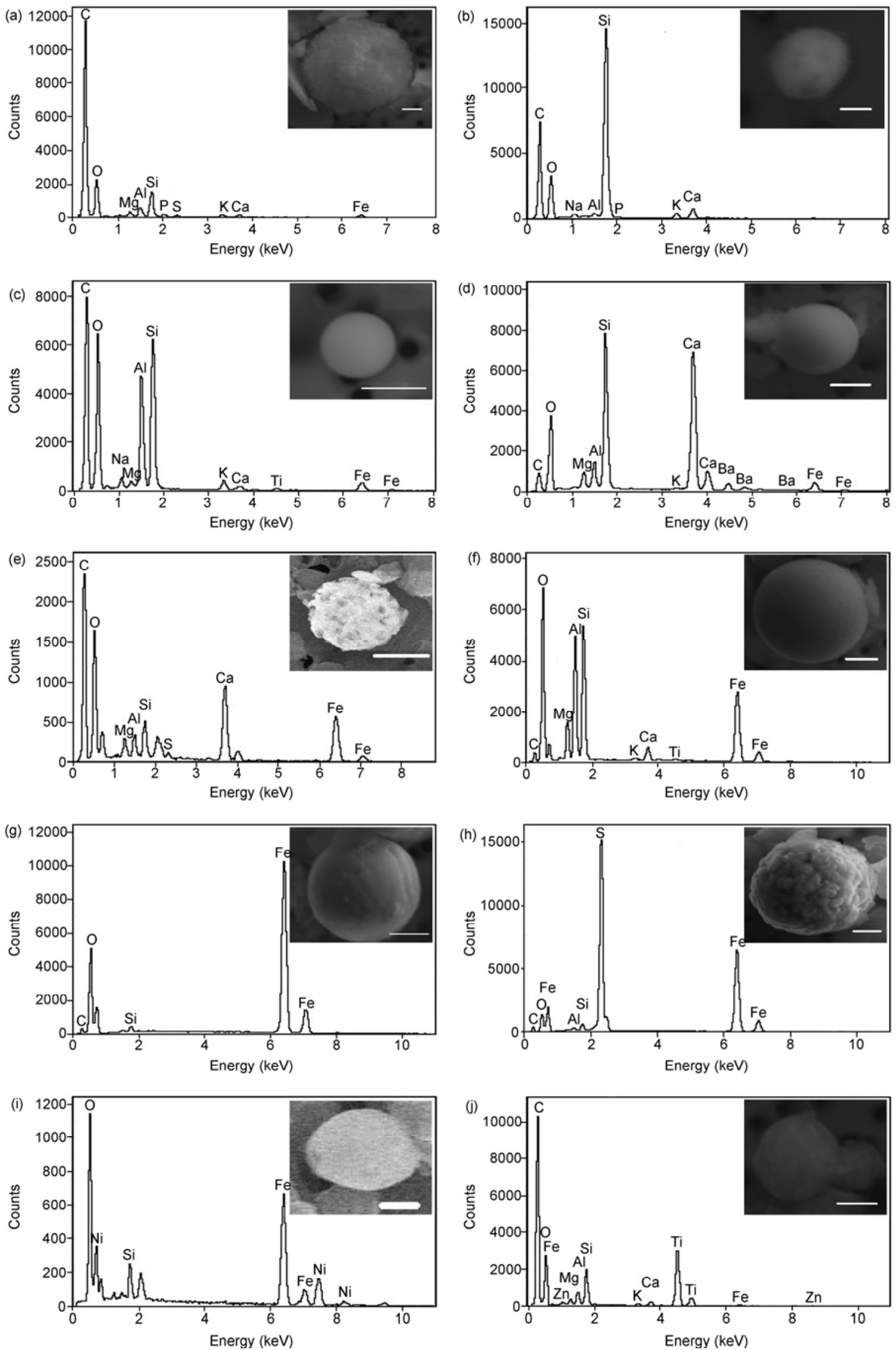

Figure 3 EDX spectra of fly ash particles with different morphologies (the scale is $1 \mu \mathrm{m}$ ). 

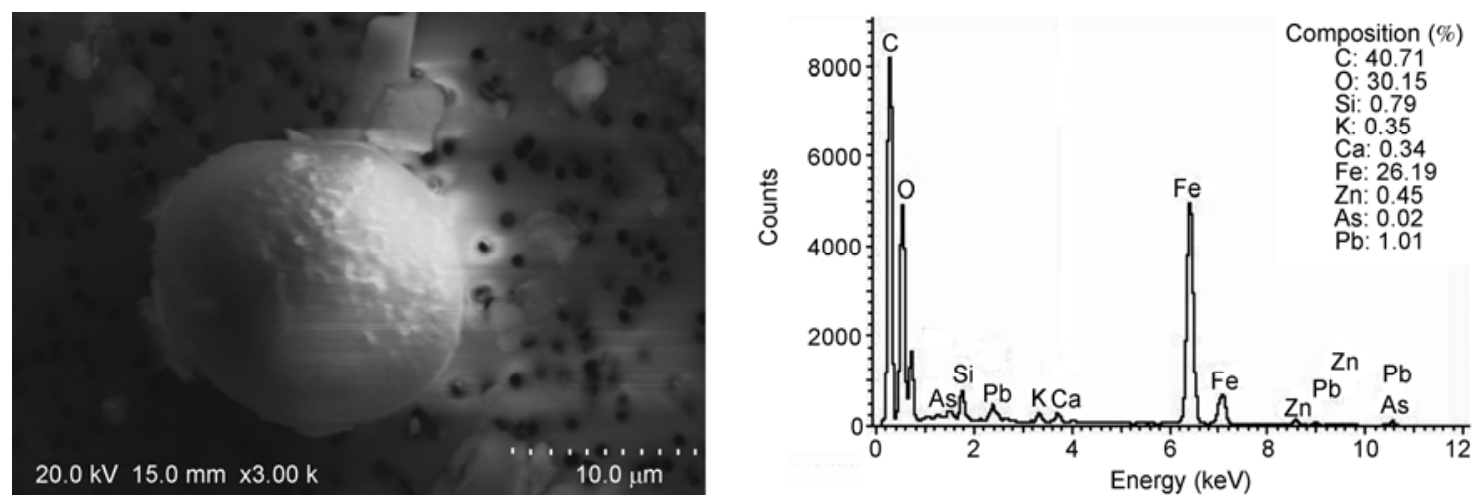

Figure 4 Photomicrograph and microanalysis corresponding to a spherical particle where heavy metal elements $(\mathrm{Fe}, \mathrm{As}, \mathrm{Pb}$ and $\mathrm{Zn})$ were observed.

Table 3 Types of fly ash particles within a $0.5-16 \mu \mathrm{m}$ radius range, evaluated by EDX

\begin{tabular}{llcccccc}
\hline Denomination & $\begin{array}{c}\text { Major } \\
\text { elements }\end{array}$ & \multicolumn{5}{c}{$\begin{array}{c}\text { Number of } \\
\text { particles }\end{array}$} & Total \\
\hline Si-dominant & & S6-36 & S6-33 & S6-29 & S6-25 & S7-15 \\
& high-Si & & 4 & 6 & 3 & 1 & 14 \\
& $\mathrm{Si}+\mathrm{Al}$ & 6 & 10 & 16 & 24 & 23 & 79 \\
& $\mathrm{Si}+\mathrm{Fe}$ & 2 & & 1 & 2 & & 5 \\
& $\mathrm{Si}+\mathrm{Ca}$ & & 2 & 1 & & & 3 \\
& $\mathrm{Si}+\mathrm{Ca}+\mathrm{Fe}$ & 2 & 1 & 1 & & & 4
\end{tabular}

Fe-dominant

$\begin{array}{lcccccc}\text { high-Fe } & 11 & 2 & 4 & 8 & 2 & 27 \\ \mathrm{Fe}+\mathrm{S} & & & & 1 & & 1 \\ \mathrm{Fe}+\mathrm{Ni} & & & & & 1 & 1\end{array}$

C-dominant

$\begin{array}{llllll}\text { high-C } & 1 & 3 & 4 & 1 & 9\end{array}$

Ti-dominant

$\mathrm{Ti}+\mathrm{Si}$ 2

Total $\begin{array}{llllll}22 & 22 & 29 & 44 & 28 & 145\end{array}$

Table 4 Melting points of different kinds of oxides

\begin{tabular}{cc||cc}
\hline Oxides & Melting point $\left({ }^{\circ} \mathrm{C}\right)$ & Oxides & Melting point $\left({ }^{\circ} \mathrm{C}\right)$ \\
\hline $\mathrm{SiO}_{2}$ & 1725 & $\mathrm{Fe}_{2} \mathrm{O}_{3}$ & 1560 \\
$\mathrm{Al}_{2} \mathrm{O}_{3}$ & 2050 & $\mathrm{TiO}_{2}$ & 1850 \\
$\mathrm{MgO}$ & 2800 & $\mathrm{CuO}$ & 1450 \\
$\mathrm{CaO}$ & 2570 & $\mathrm{NiO}_{2}$ & 2090 \\
\hline
\end{tabular}

coal industry combustion was the dominant contributor in surface snow of UG1. Fe-dominant particles were the second most common particles in samples, and their contents were even as high as those of Si-dominant particles in S6-36. Thus, we can not suggest fly ash pollution is only from one type of industrial activities (foundry and steelwork factories, coal-fired heating stations and thermal power plants). Although samples were sequentially collected according to date,

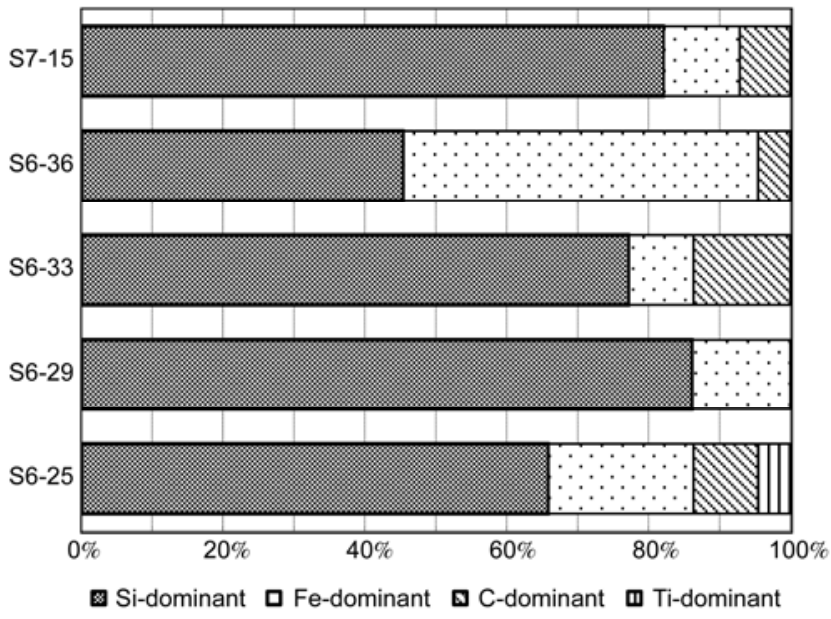

Figure 5 Percent of particles of four chemical types in five snow samples, according to EDX classification.

no regularity was observed in the chemical composition of four species. Further work will involve the collection of more samples for investigating the seasonal variability of chemical composition.

\subsection{Size distribution of fly ash particles}

When studying the morphology and chemical composition of fly ash particles, another aspect that we must consider is their size distribution. A combustion process emits fly ash particles with certain characteristics, which depend on equipment style, fuel types and operation conditions. When operating conditions change (within normal operation range), the distribution of particle size is affected, but with no different particles generated [23]. Thus, the size distribution of fly ash particles is an important parameter that can pinpoint an emission source.

The physical size of particles can be obtained by direct manual measurements on SEM images, with the assistance of the Image Pro Plus 6.0 software. The statistical results of spherical particles from the surface snow of UG1 are shown in Figure 6(a). Most size distributions of samples were mul- 
timodal, accompanied by a prominent peak. From Figure 6(a), it can be seen clearly that most samples (S6-29, S6-36 and S6-33) had maximum peaks at $2.5 \mu \mathrm{m}$. Samples S6-25, S6-33 and S6-36 also had major peaks around 3.0-6.0 $\mu \mathrm{m}$. In addition, all samples except S6-29 had minor peaks at $9.5 \mu \mathrm{m}$. An extreme example was $\mathrm{S} 7-15$, which had a prominent peak at $1.5 \mu \mathrm{m}$ and subsidiary peak at $2.5 \mu \mathrm{m}$.

If we combine Figure 5 and Figure 6(a), particle contents of prominent peaks at $2.5 \mu \mathrm{m}$ (S6-29 > S6-36 > S6-33) correspond to a tendency toward Si-dominant particles. Thus, we conclude that prominent peaks at $2.5 \mu \mathrm{m}$ represent spherical particles with Si-dominant chemical compositions, which originated from high temperature industrial coal combustion (more than $1500^{\circ} \mathrm{C}$ ). Following the same principle, major peaks around 3.0-6.0 $\mu \mathrm{m}$ indicate Fe-dominant particles from lower temperature combustion processes, and minor peaks at $9.5 \mu \mathrm{m}$ stand for the unburned C-dominant particles.

It should be noted that sample S7-15 was collected almost half a year later than the S6 series. The size distribution of sample S7-15 characterized an extremely high peak around $1.5 \mu \mathrm{m}$ and a subsidiary peak at $2.5 \mu \mathrm{m}$. Considering the relatively narrow range in size of analyzed particles from S7-15, it may be concluded that these particles were most probably a mixture of long-distance transported particles and Si-dominant particles, which had similar origins as in samples from the S6 series.

The size distributions of Fe-dominant particles and Sidominant particles in all samples are illustrated in Figure 6(b). Fe-dominant particles had larger average diameters $(3.82 \mu \mathrm{m})$ than the Si-dominant particles $(3.24 \mu \mathrm{m})$, indicating that Fe-dominant particles were easier to form and formed earlier in the furnace, due to the differential melting points of compositional oxides (Table 4). C-dominant particles with average diameters of $8.43 \mu \mathrm{m}$ demonstrated that the largest unburned carbon particles escaped from the furnace first. Considering the largest average diameters of C-dominant particles, we assume that they resulted from the proximal combustion of residential heating.

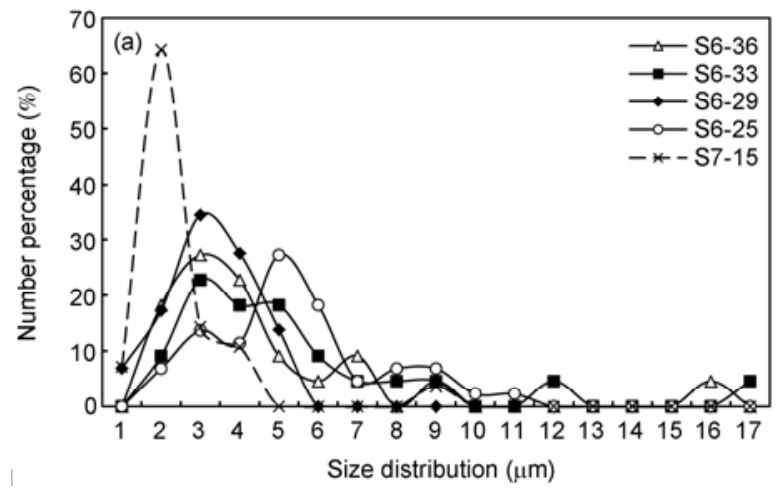

\subsection{Possible sources of particles}

To identify potential transport pathways and possible sources of spherical particles at UG1, air mass backward trajectories were calculated using the vertical velocity method by the Hybrid Single-Particle Lagrangian Integrated Trajectory (HYSPLIT) model of the Air Resources Laboratory of NOAA, http://www.arl.noaa.gov/ready/hysplit4.html [42]. HYSPLIT back-trajectories have been widely used in previous studies [9,11,19,43].

Figure 7 shows 3-day backward trajectories terminated at $500 \mathrm{~m}$ above the ground of the field observation site at UG1 for each sample during the sampling period. It can be seen that most of the air masses came from the west, agreeing well with the prevailing westerlies. All the air masses of the S6 series passed through the developed urban areas of central Asia (e.g. Almaty, the capital city of Kazakhstan; Bishkek, the capital city of Kyrgyzstan; Tashkent, the capital city of Uzbekistan), which may have contributed to the abundant fly ash particles of industrial combustion. The most intensive fluxes of heavy metals were disclosed in areas of few industrial point sources (metallurgical industries and coal-fired power plants) in central and eastern Kazakhstan and in Uzbekistan, which provided about $80 \%$ to $90 \%$ of the total anthropogenic heavy metals in the ambient air over central Asia [44,45]. Previous research has shown that synoptic processes prevalent in the central Tian shan occurred from the west, suggesting that aerosol particles from western Kyrgyzstan, Kazakhstan, Uzbekistan and Turkmenistan may be transported eastwards [46]. Another possible source of these pollutants is the city of Urumqi, which is located northeast of the sampling site. However, it also can be seen from Figure 7 that the dominant transport pathways over this region did not pass over the urban area of Urumqi. Thus, the anthropologic particles, which originated from Urumqi to our observation site were not significant, this is consistent with the analytical results of aerosol samples collected from UG1[43]. The backward trajectories of S7-15 combined with the narrow and small size distribution

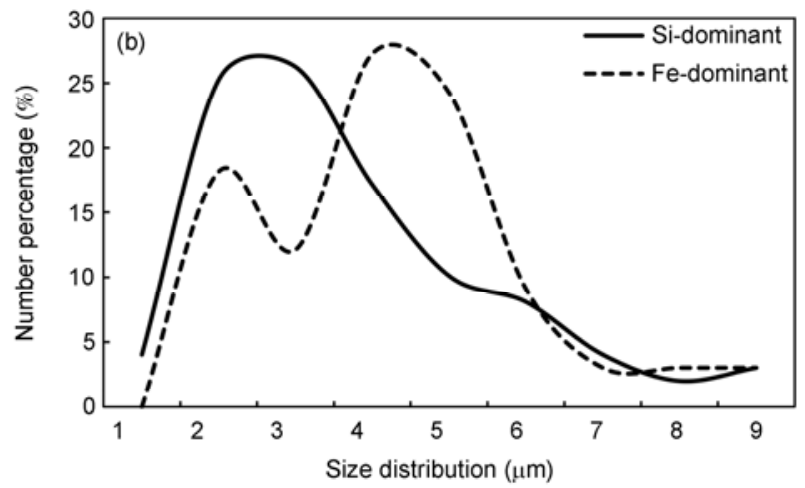

Figure 6 (a) Relative percentage and size distribution of fly ash particles in samples collected from surface snow at UG1; (b) relative percentage and size distributions of Fe-dominant and Si-dominant fly ash particles in all five snow samples. 

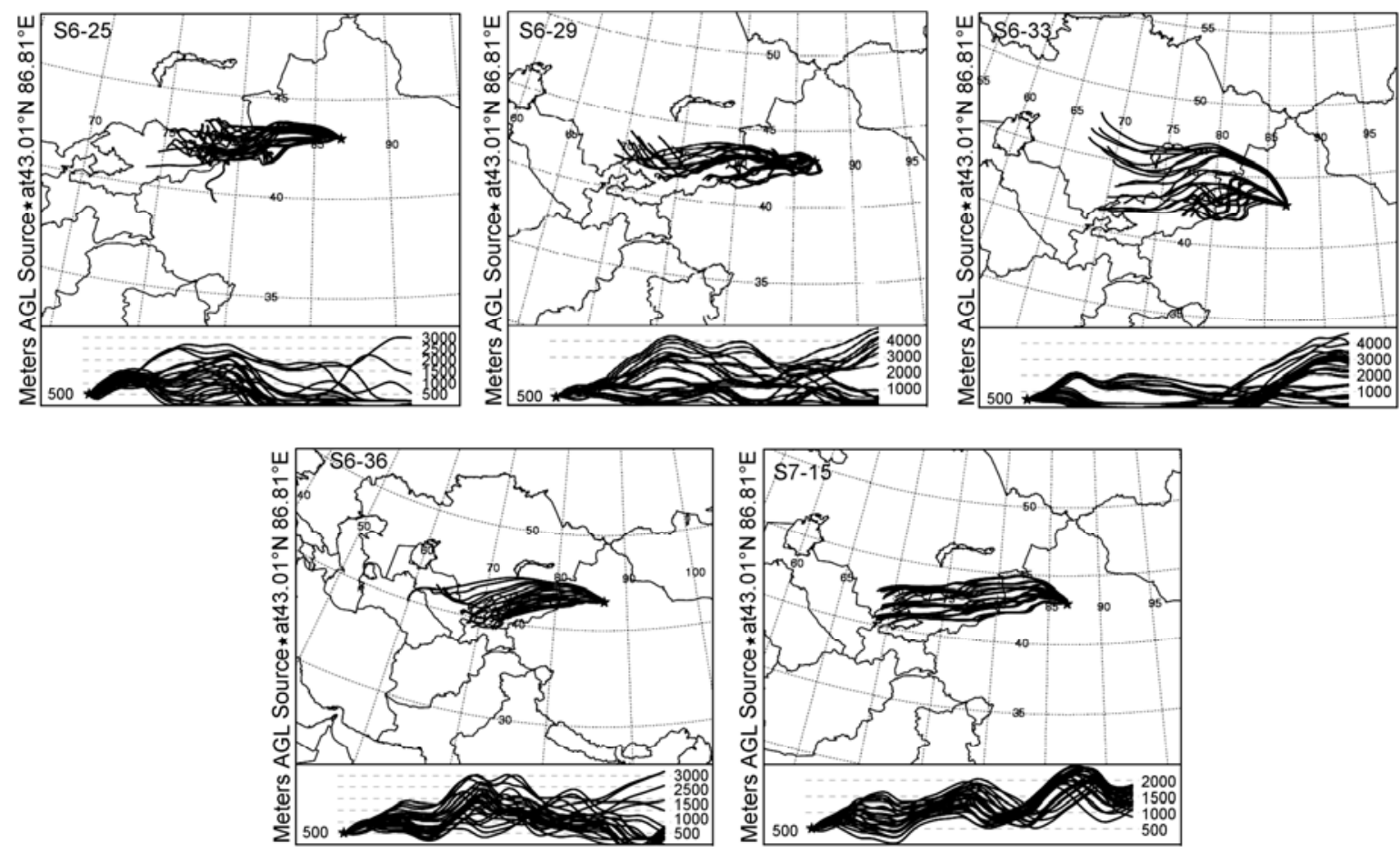

Figure 7 Three-day backward trajectories terminated at $500 \mathrm{~m}$ above the ground level of the field observation site at Urumqi Glacier No.1.

indicate that these particles represented long-range transport by the dominant westerly circulation system in the summer.

\section{Conclusions}

Spherical fly-ash particles derived from insoluble particles in surface snow at UG1 from 2006 to 2007 were characterized using SEM-EDX to obtain information regarding the size, elemental composition and morphological properties of individual particles. Most of the fly-ash particles were spherical and spheroidal with sizes smaller than $10 \mu \mathrm{m}$ (PM 10). Some were enriched with heavy metal elements that were difficult to associate with the natural environment. Because of their vitreous nature and elemental composition, these particles were associated with an industrial origin. On the basis of the chemical information presented by EDX, the dominant fly ash particles were classified as Si-dominant, Fe-dominant, Ti-dominant and C-dominant particles. All of the spherical particles (Si-dominant particles were $72.4 \%$ and Fe-dominant were about $20 \%$ ) were likely to have been emitted by anthropogenic activities, suggesting that the trace level of anthropogenic pollution to glaciers could be detected by SEM-EDX. Fly ash particles acted as one main mechanism for heavy metal pollution deposited in snow and ice of glaciers at high altitudes. Variations in size distributions, number concentrations and chemical compositions were likely attributed to the different origin sources. Investigation of air mass back-trajectories indicated that air masses terminating at the sampling site all passed through developed urban regions of central Asia, and these were the most likely source of the particles found at the site. The city of Urumqi also is a possible minor pollution source; however, based on the category and size of particles, the contribution of Urumqi remains unclear.

Finally, it should be noted that spherical particles can act as effective pollution tracers of industrial combustion in the atmospheric environment. This is because of the morphology, size distribution and chemical composition of the inorganic fly-ash spheres could be obtained by snowfall. Thus these inorganic fly-ash spheres provide a guide to determine the origin of certain species and for locating sources of emission.

We thank PGPI members of Tianshan Glaciological Station for their assistance with the field work. We are grateful to the editor and anonymous reviewers for their critical and helpful comments. This work was supported by the National Natural Science Foundation of China (40871046, 40571038 and 4081019001) and the Knowledge Innovation Program of the Chinese Academy of Sciences (KZCX2-YW-146).

1 Rose N L. Fly-ash Particles in Tracking Environmental Change Using Llake Sediments. New York: Springer, 2001. 319-349

2 Alliskaar T. Spatial and temporal variability of the distribution of spherical fly-ash particles in sediments in Estonia. Dissertation for the Doctoral Degree. Tallinn: Tallinn Pedagogical University, 2000. 37-116

3 Rose N L, Harlock S, Appleby P G. The spatial and temporal distributions of spheroidal carbonaceous fly-ash particles (SCP) in the sediment records of European mountain lakes. Water Air Soil Pollut, 
1999, 113: 1-32

4 Wik M, Renberg I. Environmental records of carbonaceous fly-ash particles from fossil fuel combustion. J Paleolimnol, 1996, 15: 193-206

5 Zhou K, Xu M H, Yu D X, et al. The effects of coal blending on the formation and properties of particulate matter during combustion. Chinese Sci Bull, 2010, 55: 3448-3455

6 Ducret J, Cachier H. Particulate carbon in rain at various temperate and tropical locations. Atmos Chem, 1992, 15: 55-67

7 Pöschl U. Atmospheric aerosols: Composition, transformation, climate and health effects. Angewandte Chemie, 2005, 44: 752-754

8 Hicks S, Isaksson E. Assessing source areas of pollutants from studies of fly ash, charcoal, and pollen from Svalbard snow and ice. J Geophys Res, 2006, 111: D02113

9 Cong Z Y, Kang S C, Dong S P, et al. Elemental and individual particle analysis of atmospheric aerosols from high Himalayas. Environ Monit Assess, 2010, 160: 323-335

10 Schöner W, Staudinger M, Winiwarter W, et al. Dating of snow samples from snow pits at Sonnblick, Austrian Alps as a tool for interpretation of chemical analysis. The Proceedings of EUROTRAC Symposium '92, SPB: Academic Publishing, 1993. 753-756

11 Flanner M G, Zender C S, Randerson J T, et al. Present-day climate forcing and response from black carbon in snow. $\mathrm{J}$ Geophys Res, 2007, 112: D11202

12 Sun A Z, Ma Y Z, Feng Z D, et al. Pollen-recorded climate changes between 13.0 and $7.0{ }^{14} \mathrm{C}$ ka BP in southern Ningxia, China. Chinese Sci Bull, 2007, 52: 1080-1088

13 Bourgeois J C, Gajewski K, Koerner R M. Spatial patterns of pollen deposition in Arctic snow. J Geophys Res, 2001, 106: 5255-5565

14 Short S K, Holdsworth G. Pollen, oxygen isotope content and seasonality in an ice core from the Penny Ice Cap, Baffin Island. Arctic, 1985, 38: 214-218

15 Xu B Q, Wang M, Joswiak D R, et al. Deposition of anthropogenic aerosols in a southeastern Tibetan glacier. J Geophys Res, 2009, 114: D17209

16 Wu G J, Yao T D, Xu B Q, et al. Seasonal variations of dust record in the Muztagata ice cores. Chinese Sci Bull, 2008, 53: 2506-2512

17 Marinoni A, Cristofanelli P, Laj P, et al. Aerosol mass and black carbon concentrations, two year-round observations at NCO-P (5079 m, Southern Himalayas). Atmos Chem Phys Discuss, 2010, 10: 83798413

18 Lau K M, Kim M K, Kim K. Enhanced surface warming and snow melt in the Himalayas and Tibetan Plateau induced by the EHP effect. Environ Res Lett, 2010, 5: 025204

19 Wu G J, Zhang X L, Zhang C L, et al. Concentration and composition of dust particles in surface snow at Urumqi Glacier No. 1, Eastern Tien Shan. Glob Planet Change, 2010, 74: 34-42

20 Zamengo L, Barbiero N, Gregio M, et al. Combined scanning electron microscopy and image analysis to investigate airborne submicron particles: A comparison between personal samplers. Chemosphere, 2009, 76: 313-323

21 Goldstein J. Scanning Electron Microscopy and X-ray Microanalysis. New York: Kluwer, 2003. 1-223

22 Slezakova K, Pires J C M, Pereira M C, et al. Influence of traffic emissions on the composition of atmospheric particles of different sizes-Part 2: SEM-EDS characterization. J Atmos Chem, 2008, 60: 221-236

23 Umbria A, Galán M, Muñoz M J, et al. Characterization of atmospheric particles: Analysis of particles in the Campo de Gibraltar. Atmósfera, 2004, 17: 191-206

24 Tasić M, Branislava D S, Slavica R, et al. Physico-chemical characterization of PM10 and PM2.5 in the Belgrade urban area. Acta Chim Slov, 2006, 53: 401-405

25 Neinavaie H, Pirkl H, Trimbacher C. Herkunft und Charak-teristik von Stäuben: Research Report. Umweltbundesamt, Wien, 2000. 1-61

26 Sokol E V, Kalugin V M, Nigmatulina E N, et al. Ferrospheres from fly ashes of Chelyabinsk coals: Chemical composition, morphology and formation conditions. Fuel, 2002, 81: 867-876

27 Massei A M, Ollivon D, Garban B, et al. PAHs in the bulk atmospheric deposition of the Seine river basin: Source identifcation and apportionment by ratios, multivariate statistical techniques and scanning electron microscopy. Chemosphere, 2007, 67: 312-321

28 Gillani N V, Kohli S, Wilson W E. Gas-to-particle conversion of sulfur in power plant plumes-I. Parametrization of the conversion rate for dry, moderately polluted ambient conditions. Atmos Environ, 1981, 15: 2293-2313

29 Zhang X L, Wu G J, Yue Y H, et al. Mineral composition and morphology of individual dust fall particulates over Lhasa in summer (in Chinese). Acta Petrol Mineral, 2011, 30: 127-134

30 Aragon, A P, Torres G V, Monroy M F, et al. Scanning electron microscope and statistical analysis of suspended heavy metal particles in San Luis Potosi, Mexico. Atmos Chem, 2000, 4: 4103-4112

31 Seames W S. An initial study of the fine fragmentation fly ash particle mode generated during pulverized coal combustion. Fuel Proc Tech, 2003, 81: 109-125

32 Zhang C, Yao Q, Sun J. Characteristics of particulate matter from emissions of four typical coal-fired power plants in China. Fuel Proc Tech, 2005, 86: 757-768

33 Choël M, Deboudt K, Flament P, et al. Single-particle analysis of atmospheric aerosols at Cape Gris-Nez, English Channel: Infuence of steel works on iron apportionment. Atmos Chem, 2007, 41: 28202830

34 Zhao Y C, Zhang J Y, Liu J, et al. Study on mechanism of mercury oxidation by fly ash from coal combustion. Chinese Sci Bull, 2010, 55: $163-167$

35 Meji R. Trace element behavior in coal-fired power plant. Fuel Proc Tech,1994, 39: 199-217

36 Goodarzi F, Sanei H, Duncan W F. Monitoring the distribution and deposition of trace elements associated with a zinc-lead smelter in the Trail area, British Columbia, Canada. J Environ Monit, 2001, 3: $15-25$

37 Goodarzi F. Characteristics and composition of fly ash from Canadian coal-fired power plants. Fuel, 2006, 85: 1418-1427

38 Hinkley T, Pertsiger F, Zavjalova L. The modern atmospheric background dust load: Recognition in Central Asian snowpack, and compositional constraints. Geophys Res Lett, 1997, 24: 1607-1610

39 Lee X Q, Qin D H, Jiang G B, et al. Atmospheric pollution of a remote area of Tianshan Mountains: Ice core record. J Geophys Res, 2003, 108: 4406

$40 \mathrm{Xu} \mathrm{J} \mathrm{Z,} \mathrm{Hou} \mathrm{S} \mathrm{G,} \mathrm{Chen} \mathrm{F} \mathrm{K,} \mathrm{et} \mathrm{al.} \mathrm{Tracing} \mathrm{the} \mathrm{sources} \mathrm{of} \mathrm{particles} \mathrm{in}$ the East Rongbuk ice core from Mt. Qomolangma. Chinese Sci Bull, 2009, 54: 1781-1785

41 McConnell J R, Edwards R. Coal burning leaves toxic heavy metal legacy in the Arctic. Proc Natl Acad Sci USA, 2008, 105: 1214012144

42 Draxler R R, Rolph G D. An overview of the HYSPLIT_4 modeling system of trajectories, dispersion, and deposition. Aust Meteorol Mag, 1998, 47: 295-308

43 Li Z Q, Zhao S H, Edwards R, et al. Characteristics of individual aerosol particles over Urumqi Glacier No.1 in eastern Tianshan, central Asia, China. Atmos Res, 2011, 99: 57-66

44 Gromov S, Ginzburg V. Estimation of heavy metal emissions from coal-fired power plants in Russia. Adv Air Pollut, 1998, 5: 597-606

45 Kakareka S, Gromov S, Pacyna J, et al. Estimation of heavy metal emission fluxes on the territory of the NIS. Atmos Environ, 2004, 38: 7101-7109

46 Aizen V B, Aizen E M, Melack J M, et al. Association between atmospheric circulation patterns and firn-ice core records from the Inilchek glacierized area, central Tien Shan, Asia. J Geophys Res, 2004,109: D08304

Open Access This article is distributed under the terms of the Creative Commons Attribution License which permits any use, distribution, and reproduction in any medium, provided the original author(s) and source are credited. 